http://dx.doi.org/10.32929/2446-8355.2020v29n2p274-288

\title{
ESCALAS DIAGRAMÁTICAS PARA AVALIAÇÃO DO FENÓTIPO DE TUBÉRCULOS DE BATATA
}

\begin{abstract}
Marcio Lisboa Guedes ${ }^{1 *}$, Mario Henrique Murad Leite Andrade ${ }^{2}$, Rafael Ravaneli Chagas ${ }^{3}$, Rafaela Pereira Carvalho ${ }^{4}$, Cláudio Carlos Fernandes Filho ${ }^{5}$, César Augusto Brasil Pereira Pinto $^{6}$
\end{abstract}

\footnotetext{
${ }^{1}$ Pós-doutorando, Genética e Melhoramento de Plantas, Universidade Federal de Goiás (UFG), Goiânia, GO.

*E-mail do autor correspondente: marcioguedesbio@gmail.com

${ }^{2}$ Doutor, Genética e Melhoramento de Plantas, Universidade Federal de Lavras (UFLA), Lavras, MG.

${ }^{3}$ Doutorando, Genética e Melhoramento de Plantas, Universidade Federal de Viçosa (UFV), Viçosa, MG.

${ }^{4}$ Mestre, Genética e Melhoramento de Plantas, Universidade Federal de Lavras (UFLA), Lavras, MG.

${ }^{5}$ Doutorando, Genética e Melhoramento de Plantas pela Universidade Federal de Lavras (UFLA), Lavras, MG.

${ }^{6}$ Docente, Universidade Federal de Lavras (UFLA), Lavras, MG.
}

Recebido: 27/03/2020; Aceito: 12/06/2020

\begin{abstract}
RESUMO: Nos programas de melhoramento de batata existem diversos caráteres dos tubérculos que são avaliados com o auxílio de escalas diagramáticas. Entretanto, não há padronização das escalas entre os programas de melhoramento, fazendo com que cada programa adote a sua própria escala. O objetivo do trabalho foi elaborar e validar diferentes escalas diagramáticas para avaliação de caracteres relacionados ao fenótipo de tubérculos de batata. Foram considerados os caracteres: textura da periderme; formato; profundidade de olhos; coloração de polpa; coloração de palito após a fritura; coloração de "chips" após a fritura e coloração de pele. Dez avaliadores atribuíram notas aos tubérculos para os caracteres sem e com o uso das escalas. Foram avaliadas dez repetições classificadas em cada nota da respectiva escala utilizando o delineamento inteiramente casualizado. Os dados de todos avaliadores foram submetidos à análise de regressão linear entre as notas reais e as médias das notas dos avaliadores sem e com o uso da escala. Quando a avaliação foi realizada com o uso das escalas, todos os avaliadores melhoraram sua precisão, com aumento nos coeficientes de determinação para todos os caracteres estudados. Essas escalas apresentam-se como uma ferramenta bastante oportuna para auxiliar nas avaliações dos caracteres que compõe a aparência geral dos tubérculos, haja vista a falta de um sistema padrão de avaliação.
\end{abstract}

Palavras-chave: Solanum Tuberosum L. Melhoramento genético. Elaboração. Validação.

\section{DIAGRAMMATICS SCALES TO EVALUATION OF THE PHENOTYPE OF POTATO TUBERS}

\begin{abstract}
In potato breeding programs there are several characters of the tubers that are evaluated with the aid of diagrammatic scales. However, there is no standardization of scales between breeding programs, making each program adopt its own scale. The objective of the work was to elaborate and validate different diagrammatic scales for character evaluation related to the potato tuber phenotype. The characters were considered: tuber skin texture; shape; tuber eyes depth; internal flesh color; color of French fries; color of chips and tuber skin color.
\end{abstract}


Ten evaluators rated the tubers for the characters without and with the use of scales. Ten repetitions classified in each note of the respective scale were evaluated using a completely randomized design. The data of all evaluators were submitted to the linear regression analysis between the actual scores and the means of the evaluators' scores without and with the use of the scale. When an evaluation was performed using the scales, all the evaluators improved their accuracy, with the determination coefficient values for all the characters studied. These scales are presented as a very efficient tool to support in the character evaluations that make up a general appearance of the tubers, given the lack of a standard evaluation system.

Key words: Solanum tuberosum L. Genetic breeding. Elaboration. Validation.

\section{INTRODUÇÃO}

A batata (Solanum tuberosum L.) é a hortaliça mais plantada no Brasil, com a produção total girando em torno de 3,8 milhões de toneladas, e rendimento médio de 30,6 t.ha- ${ }^{-1}$ (IBGE 2019). O desenvolvimento de novas cultivares de batata, além do objetivo de incrementos na produtividade e resistências às mais diversas pragas que atacam a cultura, deve estar alinhado às diferentes cadeias consumidoras (PINTO et al., 2010).

O mercado de batata no Brasil basicamente se divide em três segmentos: mercado in natura que se destina ao uso doméstico; indústria de chips e batata palha e indústria de batata pré-frita congelada, com cada segmento com suas particularidades e preferências (PINTO et al., 2010).

O consumidor de batata in natura no Brasil faz as suas escolhas baseadas em características visuais do tubérculo. A preferência dos consumidores é por tubérculos que apresentem periderme lisa e brilhante com coloração amarela, olhos rasos, formato ovalalongado, polpa creme e que sejam uniformes (HAYASHI, 2001).

Os principais atributos para tubérculos que se destinam ao processamento de batata chips e palha são basicamente alto teor de matéria seca, baixo teor de açúcares redutores, formato arredondado, olhos rasos e coloração clara após a fritura. Para a indústria de palitos pré-fritos congelados as características dos tubérculos são praticamente as mesmas atribuídas para a indústria de chips e palha. Contudo, as cores da polpa e de fritura devem ser de preferência amarelas e o formato do tubérculo deve ser alongado com tamanho acima de $75 \mathrm{~mm}$ de comprimento. Para o processamento industrial, a textura da periderme e a aparência do tubérculo são de pouca ou nenhuma importância (GARCIA, et al., 2015).

Dentre as características que compõem a aparência, destaca-se o formato dos tubérculos, podendo ser: redondo, oval ou alongado. Essa designação é determinada através do índice de formato, obtido pela fórmula: $\mathrm{IF}=$ (comprimento / diâmetro transversal) $\mathrm{x} 100$. Através desse índice, Carmo et al. (2009) classificaram os tubérculos em: Redondo (IF<125); Oval (125 < IF $<150$ ) e alongado (IF > 150). Porém existem mais classes descritas na literatura (FIGUEIREDO et al., 2011; RIBEIRO et al., 2014).

A profundidade de olhos é outro componente importante da aparência dos tubérculos. Para a comercialização in natura, tubérculos com olhos profundos apresentam pior aparência 
e, no processamento, é sinônimo de desperdício durante o processo de descascamento (LI et al. 2005).

Aliado a essas características também se têm o tipo de periderme, a qual afeta diretamente a aceitação do produto in natura pelos consumidores brasileiros. O tipo de periderme é uma das características que mais contribui para a decisão de compra de uma determinada cultivar. A periderme pode variar tanto em textura como em coloração (JEMISON, 2008), sendo a preferência do consumidor por peridermes lisas e brilhantes.

Para a avaliação de diversos caracteres de tubérculos nos programas de melhoramento de batata ou mesmo para sua comercialização, usualmente avaliadores atribuem notas utilizando escalas diagramáticas ou descritivas ou apenas utilizando a experiência adquirida ao longo dos anos. Nas instruções normativas do Ministério da Agricultura, Pecuária e Abastecimento MAPA, para os Ensaios de DHE (Distinguibilidade, Homogeneidade e Estabilidade) de cultivares de batata, existem diversos descritores para caracteres associados a planta e também ao tubérculo, entretanto, o único caráter do tubérculo que é descrito com o auxílio de escala diagramática é o formato (MAPA, 2012). Desse modo, não há padronização das escalas para os demais caracteres do tubérculo, fazendo com que cada programa adote a sua própria escala.

O objetivo desse trabalho foi desenvolver escalas diagramáticas para diferentes características associadas à aparência do tubérculo que são comumente avaliados nos programas de melhoramento de batata ou para comercialização, a fim de padronizar as notas e melhorar a precisão das avaliações.

\section{MATERIAL E MÉTODOS}

Para a elaboração das escalas foram obtidas fotos de diferentes tubérculos do programa de melhoramento genético de batata da Universidade Federal de Lavras (PROBATATAUFLA) com a câmera digital NIKON COOLPIX 16MP no mês de agosto de 2016. Em seguida, as fotos foram digitalizadas e editadas no programa Adobe Photoshop. As escalas foram elaboradas conforme as seguintes descrições:

a) Textura da periderme: foram amostrados tubérculos por meio da aparência visual e do tato, sendo: 1 = periderme áspera e fosca; 2 = periderme áspera; 3 = periderme fosca; $4=$ periderme lisa; 5 = periderme lisa e brilhante (Figura 1).

b) Formato de tubérculo: tubérculos de diferentes formatos foram medidos com uso de paquímetro digital e o índice de formato (IF) foi obtido pela razão entre comprimento (distância entre a inserção do estolão e a gema apical) / maior diâmetro transversal x 100. Os tubérculos foram classificados como: 1 = redondo, quando o IF foi menor que 105; 2 = redondo/ovalado, quando o IF foi maior que 105, porém menor que 120; 3 = oval, quando o IF foi maior que 120, porém menor que $135 ; 4=$ oval/alongado, quando o IF foi maior que 135 , porém menor que 150 e; 5 = alongado, quando o IF foi maior que 150 (Figura 2). 


\section{TEXTURA DA PERIDERME}

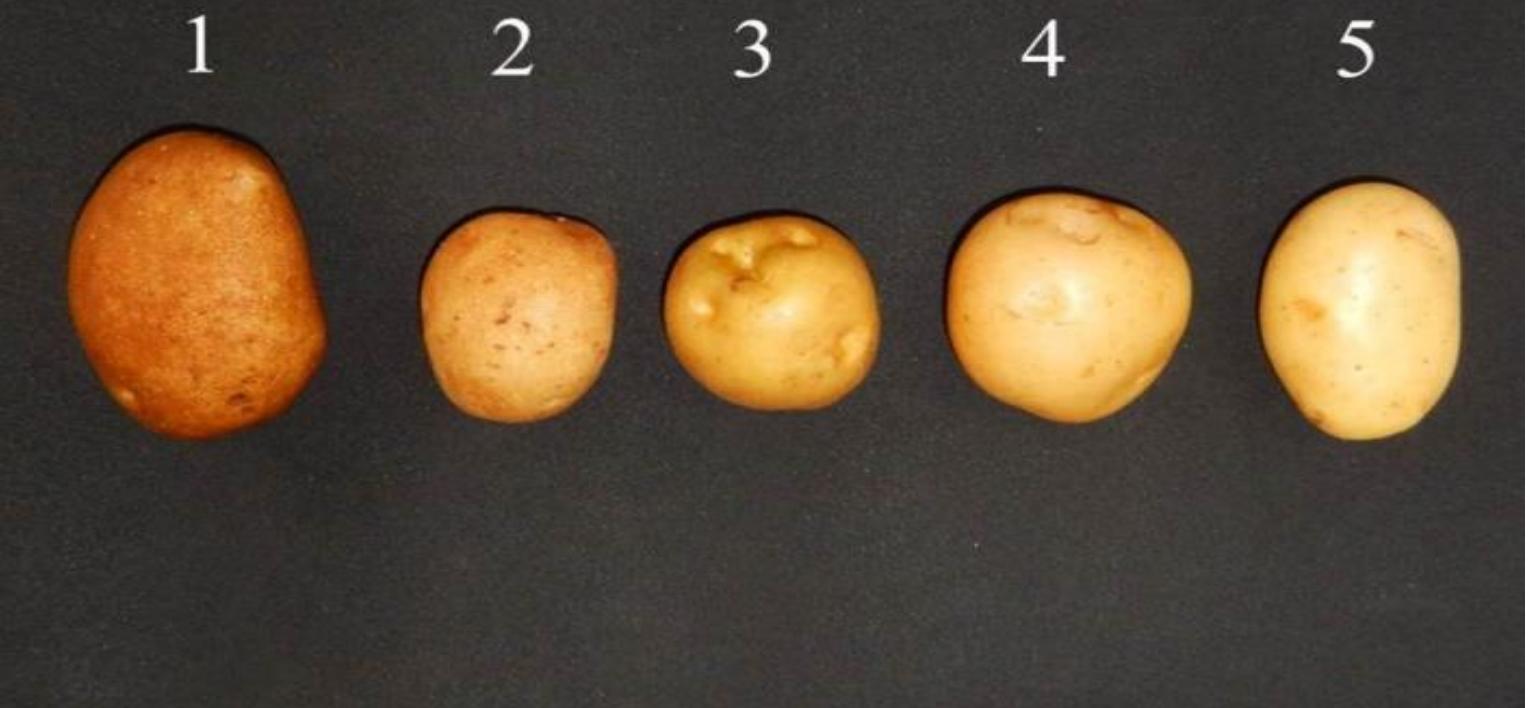

Figura 1. Escala para textura da periderme. Scale for tuber skin texture.

Fonte: Autoria própria. Own authorship.

\section{FORMATO}

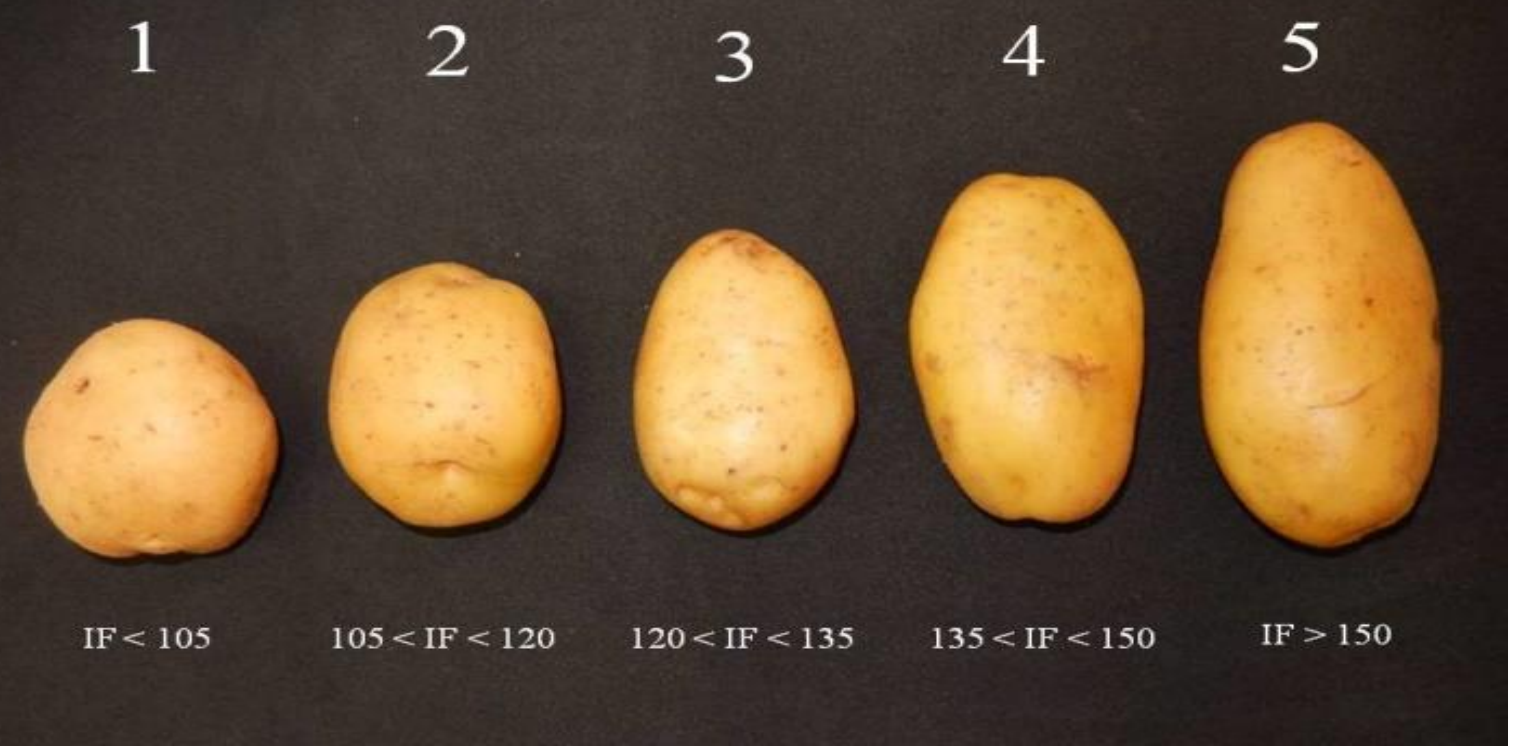

Figura 2. Escala para formato de tubérculos. Scale for tuber shape.

Fonte: Autoria própria. Own authorship.

c) Profundidade de olhos (gemas vegetativas): a profundidade das gemas apicais (P) foi mensurada utilizando paquímetro digital, sendo classificadas como: $1=\mathrm{P}>6 \mathrm{~mm} ; 2=6 \mathrm{~mm}>$ $\mathrm{P}>4 \mathrm{~mm} ; 3=4 \mathrm{~mm}>\mathrm{P}>2 \mathrm{~mm} ; 4=2 \mathrm{~mm}>\mathrm{P}>0 \mathrm{~mm}$ e $5=\mathrm{P}<0 \mathrm{~mm}$ (Figura 3).

d) Coloração de polpa: foram amostrados tubérculos com cor de polpa variando de branco (nota 1 - equivalente a nota 5Y 7/8 na tabela de Munsell); amarela clara (nota 2 - equivalente a nota 5Y 8/8 na tabela de Munsell); amarela média (nota 3 - equivalente a nota 5Y 8/6 na tabela 
de Munsell); creme (nota 4 - equivalente a nota 5Y 8/4 na tabela de Munsell) e amarela escura (nota 5 - equivalente a nota 5Y 8/2 na tabela de Munsell), (MUNSELL, 1977) (Figura 4).

\section{PROFUNDIDADE DE OLHOS}

1

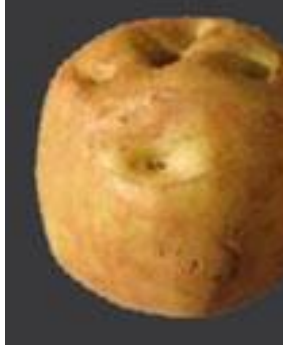

$\mathrm{P}>6 \mathrm{~mm}$
2

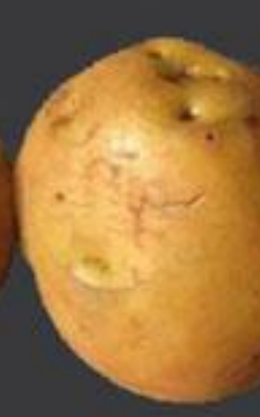

$6 \mathrm{~mm}>\mathrm{P}>4 \mathrm{~mm}$
3

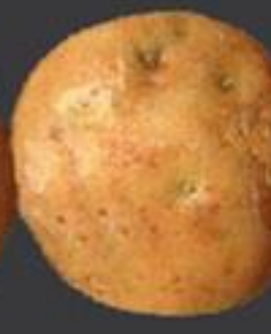

$4 \mathrm{~mm}>\mathrm{P}>2 \mathrm{~mm}$
4

5

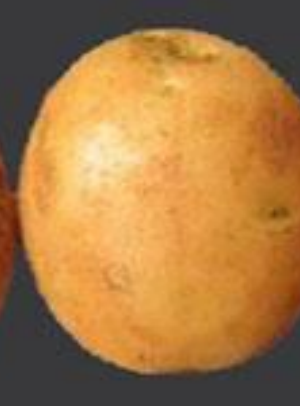

$2 \mathrm{~mm}>\mathrm{P}>0 \mathrm{~mm}$

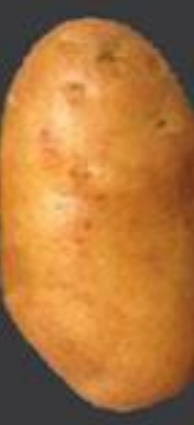

$\mathrm{P}<0 \mathrm{~mm}$

Figura 3. Escala para profundidade de olhos. Scale for tuber eyes depth.

Fonte: Autoria própria. Own authorship.

\section{COLORAÇÃO DE POLPA}

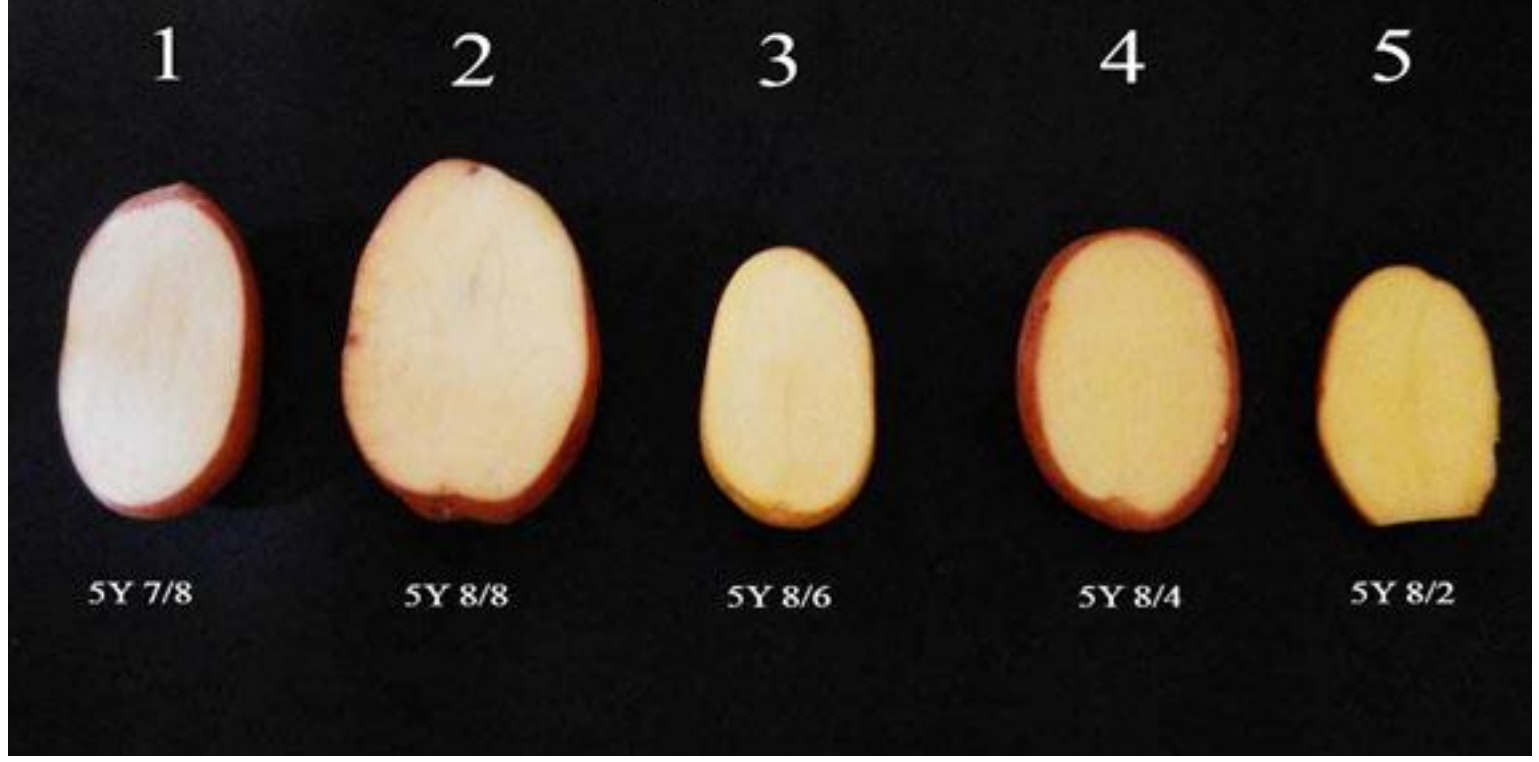

Figura 4. Escala para coloração de polpa. Scale for internal flesh color.

Fonte: Autoria própria. Own authorship.

e) Coloração de palito após a fritura: palitos centrais de diferentes tubérculos foram fritos em óleo de soja em fritadeira elétrica a $180^{\circ} \mathrm{C}$ por cinco minutos, em seguida, eles foram classificados em diferentes notas variando de cor amarela clara (nota 1 - equivalente a nota 2,5Y 8/4 na tabela de Munsell); amarela média (nota 2 - equivalente a nota 2,5Y 8/6 na tabela 
de Munsell); amarela escura (nota 3 - equivalente a nota 2,5Y 8/8 na tabela de Munsell); marrom claro (nota 4 - equivalente a nota 7,5YR 6/8 na tabela de Munsell) e marrom escuro (nota 5 equivalente a nota 7,5Y 4/6 na tabela de Munsell), (MUNSELL, 1977) (Figura 5).

\section{COLORAÇÃO DE PALITO APÓS A FRITURA}

1

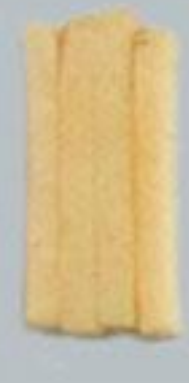

2,5 Y $8 / 4$
2

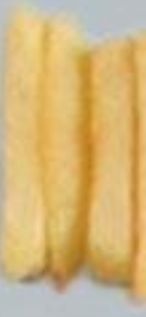

2,5 Y $8 / 6$
3

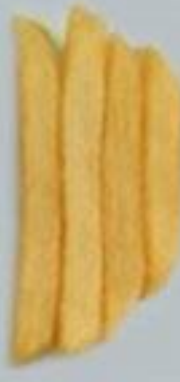

2,5 Y $8 / 8$
4

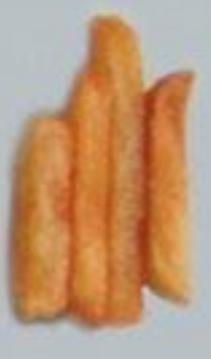

7,5 YR $6 / 8$
5

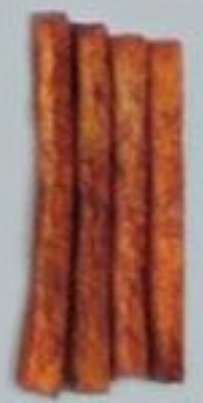

7,5 Y $4 / 6$

Figura 5. Escala para coloração de palito após a fritura. Scale for color of French fries.

Fonte: Autoria própria. Own authorship.

f) Coloração de "chips" após a fritura: fatias transversais de $3 \mathrm{~mm}$ de espessura foram cortados de diferentes tubérculos, fritos em óleo de soja em fritadeira elétrica a $180^{\circ} \mathrm{C}$ por quatro minutos e classificados em diferentes notas variando de cor amarela clara (nota 1 equivalente a nota 10YR 8/4 na tabela de Munsell); creme (nota 2 - equivalente a nota 10YR 8/6 na tabela de Munsell); marrom claro (nota 3 - equivalente a nota 10YR 7/8 na tabela de Munsell); marrom (nota 4 - equivalente a nota 10YR 5/8 na tabela de Munsell) e marrom escura (nota 5 - equivalente a nota 10YR 4/6 na tabela de Munsell), (MUNSELL, 1977) (Figura 6).

g) Coloração de pele: foram amostrados tubérculos com cor de pele variando de cor creme (nota 1 - equivalente a nota 7,5YR 8/6 na tabela de Munsell); bege claro (nota 2 - equivalente a nota 7YR 7/3 na tabela de Munsell); vermelho claro (nota 3 - equivalente a nota 7,5YR 6/4 na tabela de Munsell); vermelho (nota 4 - equivalente a nota 7,5YR 4/3 na tabela de Munsell) e vermelho intenso (nota 5 - equivalente a nota 7,5YR 3/3 na tabela de Munsell), (MUNSELL, 1977) (Figura 7). 


\section{COLORAÇÃO DE CHIPS APÓS A FRITURA}

1

2

3

4

5
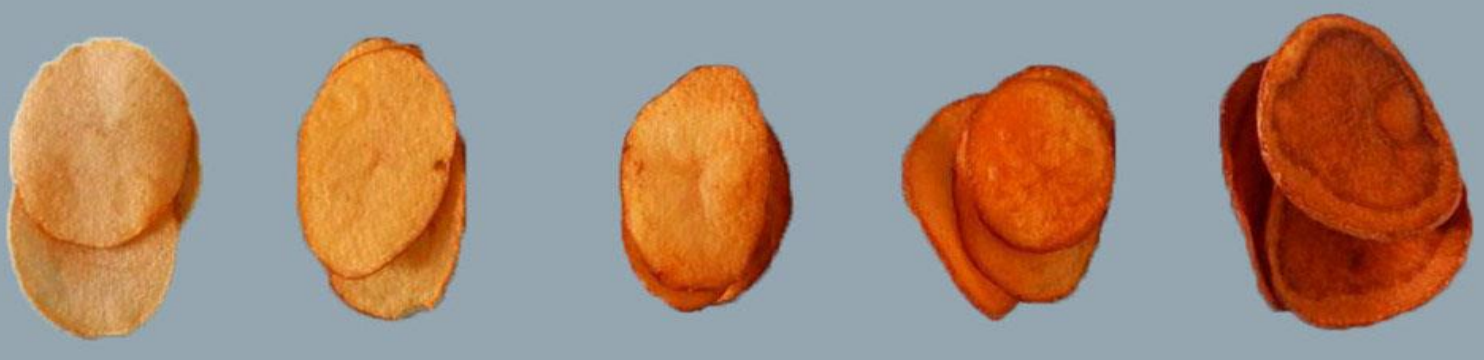

10YR $8 / 4$

10YR $8 / 6$

10YR $7 / 8$

10YR $5 / 8$

10YR 4/6

Figura 6. Escala para coloração de chips após a fritura. Scale for color of potato chips. Fonte: Autoria própria. Own authorship.

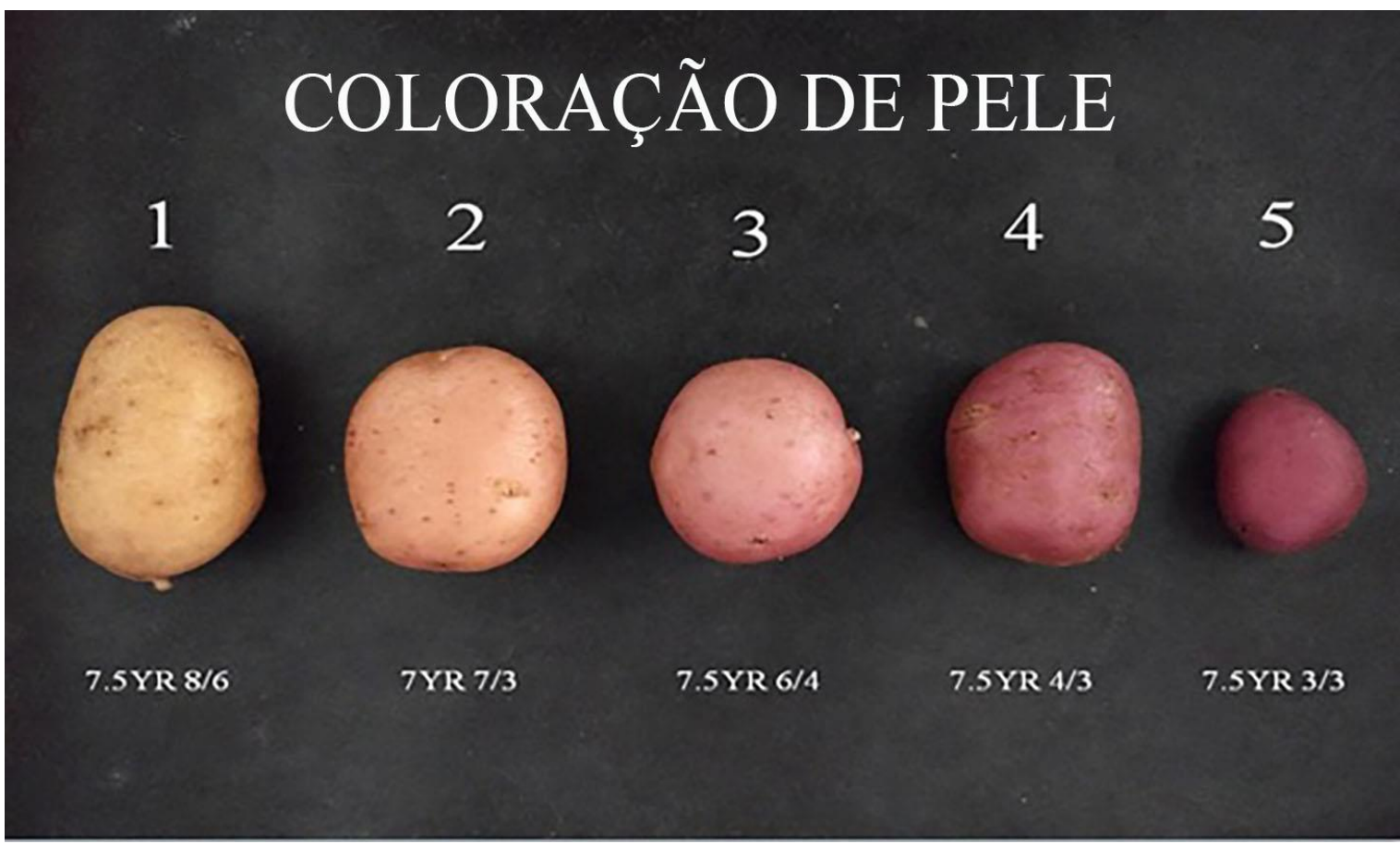

Figura 7. Escala para coloração de pele. Scale for tuber skin color.

Fonte: Autoria própria. Own authorship.

Para validação das escalas propostas, dez avaliadores atribuíram notas em tubérculos para todas as características sem o uso das escalas e posteriormente auxiliados através das escalas propostas. Foram escolhidos cinco avaliadores experientes (com pelo menos dois anos de experiência com a avaliação da aparência de tubérculos de batata) e cinco avaliadores não experientes (sem qualquer contato prévio com a avaliação da aparência de tubérculos de batata). 
Para cada característica foram avaliadas dez repetições (tubérculos) classificados em cada nota da respectiva escala. Para cada característica os cinquenta tubérculos (10 repetições x 5 notas) foram aleatorizados em delineamento inteiramente casualizado.

Para a primeira avaliação - sem o auxílio da escala, os avaliadores não experientes foram previamente instruídos em como realizar a classificação para cada uma das características. Já para os avaliadores experientes as notas foram atribuídas de acordo com a sua experiência prévia adquirida no trabalho rotineiro no programa de melhoramento de batata da UFLA. Posteriormente, na segunda avaliação, os mesmos avaliadores, experientes e não experientes, avaliaram os mesmos tubérculos, porém agora com o auxílio das escalas propostas.

Os dados de todos os avaliadores foram submetidos à análise de regressão linear entre as notas previamente estabelecidas (nota real) (variável independente) e as médias das notas dos avaliadores sem e com o uso da escala (variáveis dependentes). O coeficiente angular (b) de cada regressão linear foi comparado pelo teste $t(p<0,05)$ para todos os dez avaliadores e também separado em grupos: avaliadores experientes e não experientes sem e com o uso das escalas.

A precisão dos avaliadores foi obtida pelo coeficiente de determinação da regressão $\left(\mathrm{R}^{2}\right)$ e pela dispersão dos resíduos da regressão estimados sem e com o uso das escalas (CAMPBELL; MADDEN, 1990). Além disso, foram realizadas as porcentagens de coincidência da nota real com a nota atribuída pelos avaliadores sem e com o uso das escalas. As análises estatísticas utilizadas foram computadas utilizando o programa computacional $\mathrm{R}$ (TEAM, 2017).

\section{RESULTADOS E DISCUSSÃO}

Para todas as características estudadas, comparando todos os avaliadores (experientes e não experientes) sem uso das escalas foram observados que os valores do coeficiente angular (b) foram estatisticamente diferentes de 1,0 (Tabela 1). Sem o uso das escalas diagramáticas, as equações de regressão apresentaram valores de coeficientes de determinação variando de 0,79 até 0,95 para coloração de polpa e coloração de "chips" após a fritura, respectivamente (Tabela 1). Para a distribuição dos resíduos das avaliações realizadas sem o uso das escalas foi observado que a média dos erros de todos os caracteres para todos os avaliadores variou entre - 0,93 a 0,82, como exemplo, a variação dos resíduos para profundidade de olhos foi entre 0,70 a 0,90 (Figura 8 ).

Nutter Junior et al. (1991) explicam que precisão é a medida de confiabilidade nas avaliações, podendo ser quantificada pelo coeficiente de determinação de regressões lineares estabelecidas entre a nota real e a nota estimada. Quanto maiores os valores do $\mathrm{R}^{2}$, mais preciso é o avaliador. A situação ideal é representada por regressões lineares que apresentem valores de $\mathrm{b}$ iguais a 1 , revelando que as notas atribuídas pelos avaliadores foram iguais às notas reais $(\mathrm{y}=\mathrm{x}$ quando $\mathrm{b}=1)$.

Quando se compara os avaliadores experientes e não experientes sem o uso da escala fica evidenciado valores semelhantes de $\mathrm{R}^{2}$ para formato de tubérculos e textura da periderme (Tabela 1). Para os avaliadores experientes os valores de $\mathrm{R}^{2}$ foram maiores para profundidade 
de olhos, coloração de pele e coloração de polpa (Tabela 1). Entretanto, para coloração de "chips" e coloração de palito após a fritura os valores de $\mathrm{R}^{2}$ foram superiores para os avaliadores não experientes (Tabela 1).

Tabela 1. Coeficiente angular da reta (b) e coeficiente de determinação $\left(\mathrm{R}^{2}\right)$ das equações de regressão linear entre as notas reais e as atribuídas pelos avaliadores sem e com o uso das escalas diagramáticas. Slope $(b)$ and determination coefficient $\left(R^{2}\right)$ from the linear regression equations between the real scores and those assigned by the evaluators without and with the use of the diagrammatic scales.

\begin{tabular}{|c|c|c|c|c|}
\hline & Sem & cala & Com I & cala \\
\hline & \multicolumn{4}{|c|}{ Formato de Tubérculo } \\
\hline & $\mathrm{b}$ & $\mathrm{R}^{2}$ & $\mathrm{~b}$ & $\mathrm{R}^{2}$ \\
\hline Todos Avaliadores & $0,83^{*}$ & 0,92 & $0,86^{*}$ & 0,94 \\
\hline Avaliadores Experientes & $0,80^{*}$ & 0,92 & $0,84^{*}$ & 0,94 \\
\hline \multirow[t]{2}{*}{ Avaliadores não Experientes } & $0,87 *$ & 0,92 & $0,87 *$ & 0,94 \\
\hline & \multicolumn{4}{|c|}{ Textura da Periderme } \\
\hline Todos Avaliadores & $0,73^{*}$ & 0,90 & $0,85^{*}$ & 0,95 \\
\hline Avaliadores Experientes & $0,75^{*}$ & 0,92 & $0,86^{*}$ & 0,96 \\
\hline \multirow[t]{2}{*}{ Avaliadores não Experientes } & $0,71^{*}$ & 0,92 & $0,85^{*}$ & 0,96 \\
\hline & \multicolumn{4}{|c|}{ Profundidade de Olhos } \\
\hline Todos Avaliadores & $0,80^{*}$ & 0,90 & $0,83^{*}$ & 0,96 \\
\hline Avaliadores Experientes & $0,82 *$ & 0,93 & $0,83 *$ & 0,98 \\
\hline \multirow[t]{2}{*}{ Avaliadores não Experientes } & $0,79 *$ & 0,88 & $0,83 *$ & 0,95 \\
\hline & \multicolumn{4}{|c|}{ Coloração de Pele } \\
\hline Todos Avaliadores & $0,76^{*}$ & 0,90 & $0,82 *$ & 0,94 \\
\hline Avaliadores Experientes & $0,81^{*}$ & 0,93 & $0,84 *$ & 0,94 \\
\hline \multirow[t]{2}{*}{ Avaliadores não Experientes } & $0,71^{*}$ & 0,90 & $0,80 *$ & 0,94 \\
\hline & \multicolumn{4}{|c|}{ Coloração de Polpa } \\
\hline Todos Avaliadores & $0,64^{*}$ & 0,79 & $0,82 *$ & 0,89 \\
\hline Avaliadores Experientes & $0,72 *$ & 0,87 & $0,81 *$ & 0,88 \\
\hline \multirow[t]{2}{*}{ Avaliadores não Experientes } & $0,55^{*}$ & 0,74 & $0,83 *$ & 0,90 \\
\hline & \multicolumn{4}{|c|}{ Coloração de Chips Após a Fritura } \\
\hline Todos Avaliadores & $0,92 *$ & 0,95 & $0,95 *$ & 0,97 \\
\hline Avaliadores Experientes & $0,87 *$ & 0,93 & $0,90 *$ & 0,96 \\
\hline \multirow[t]{2}{*}{ Avaliadores não Experientes } & 0,97 & 0,97 & 1,00 & 0,99 \\
\hline & \multicolumn{4}{|c|}{ Coloração de Palito Após a Fritura } \\
\hline Todos Avaliadores & $0,83^{*}$ & 0,91 & $0,89 *$ & 0,96 \\
\hline Avaliadores Experientes & $0,80^{*}$ & 0,93 & $0,87 *$ & 0,96 \\
\hline Avaliadores não Experientes & $0,86^{*}$ & 0,88 & $0,90 *$ & 0,96 \\
\hline
\end{tabular}

*Significativo $\mathrm{b} \neq 1$ a $p<0.05$ pelo teste $\mathrm{t}$. Significant $b \neq 1$ at $p<0.05$ by $t$-test.

Fonte: Autoria própria. Own authorship. 
Todos avaliadores Profundidade de olhos-Sem escala

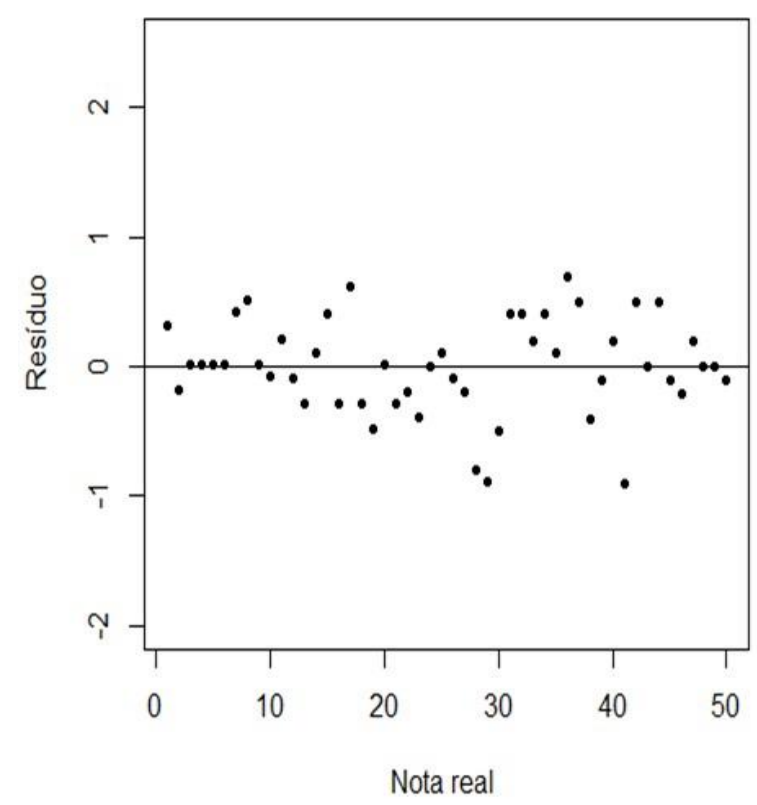

Todos avaliadores Profundidade de olhos- Com escala

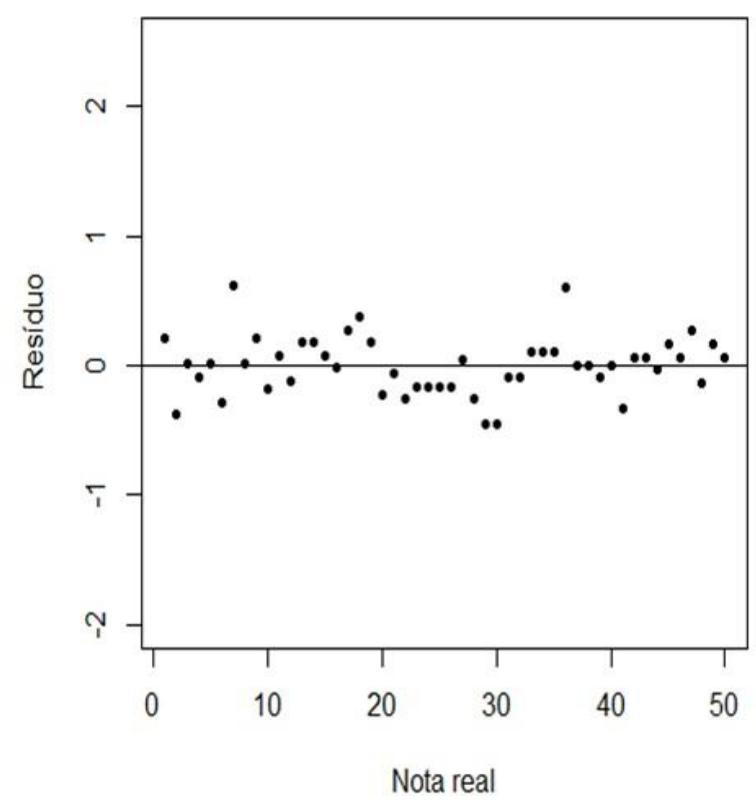

Figura 8. Resíduos da análise de regressão linear entre nota real e a média das notas atribuídas por todos avaliadores sem e com o uso da escala diagramática para profundidade de olhos. Residuals from the linear regression analysis between real note and the mean of the scores attributed by all evaluators without and with the use of the diagrammatic scale for depth of eyes.

Fonte: Autoria própria. Own authorship.

Quando a avaliação foi realizada com o uso das escalas, todos os avaliadores melhoraram sua precisão, com aumento nos coeficientes de determinação que variaram de $2 \%$ para coloração de "chips" após a fritura até 12\% para coloração de polpa (Tabela 1). Os valores do b aumentaram, se aproximando de 1 (Tabela 1). Além disso, com a utilização das escalas houve redução da dispersão dos resíduos para todos os caracteres, sendo a média dos erros de todos os avaliadores com variação entre - 0,51 a 0,69, com a menor variação para profundidade de olhos que variou entre $-0,46$ a 0,61 (Figura 8).

As escalas propostas neste trabalho se mostraram eficientes para avaliar diversos caracteres relacionados à aparência dos tubérculos de batata e para coloração de chips e palito após a fritura, uma vez que as notas de todos os avaliadores se aproximaram da nota real após a utilização das mesmas. $\mathrm{O}$ aumento na precisão após o uso de escalas diagramáticas já foi verificado por diversos autores com o emprego das mesmas para mensurar danos por pragas (JULIATTI et al. 2010; DUARTE et al. 2013; DOLINSKY et al. 2017).

Quando se compara os avaliadores experientes e não experientes com o uso das escalas fica evidenciado que os valores de $\mathrm{R}^{2}$ foram semelhantes para formato de tubérculos, textura da periderme, coloração de pele e coloração de palito após a fritura (Tabela 1). Para os avaliadores experientes os valores de $\mathrm{R}^{2}$ foram maiores para profundidade (Tabela 1). Entretanto, para coloração de "chips" após a fritura e coloração de polpa os valores de $\mathrm{R}^{2}$ foram superiores para os avaliadores não experientes (Tabela 1). 
Tabela 2. Porcentagem de coincidência de cada nota atribuída pelos avaliadores com a nota real sem o uso da escala e posteriormente com o uso da escala. Percentage of coincidence of each note attributed by the evaluators with a real note without the use of the scale and later with the use of the scale.

\begin{tabular}{|c|c|c|c|c|c|c|c|c|c|c|c|c|c|}
\hline & \multicolumn{5}{|c|}{ Sem Escala } & \multicolumn{8}{|c|}{ Com Escala } \\
\hline & \multicolumn{13}{|c|}{ Formato de Tubérculos } \\
\hline & Nota 1 & Nota 2 & Nota 3 & Nota 4 & Nota 5 & Média & Nota 1 & Nota 2 & Nota 3 & Nota 4 & Nota 5 & Média & $\Delta \%(*)$ \\
\hline Todos Avaliadores & 80 & 52 & 42 & 45 & 72 & 58,2 & 84 & 56 & 53 & 46 & 66 & 61,0 & 4,8 \\
\hline Av. Experientes & 78 & 62 & 54 & 44 & 70 & 61,6 & 76 & 62 & 68 & 46 & 72 & 64,8 & 5,2 \\
\hline \multirow[t]{2}{*}{ Av. não Experientes } & 82 & 42 & 30 & 46 & 74 & 54,8 & 92 & 50 & 38 & 46 & 60 & 57,8 & 5,5 \\
\hline & \multicolumn{13}{|c|}{ Textura da Periderme } \\
\hline Todos Avaliadores & 78 & 61 & 40 & 35 & 41 & 51,2 & 85 & 69 & 58 & 53 & 68 & 66,6 & 30,1 \\
\hline Av. Experientes & 74 & 62 & 52 & 42 & 52 & 56,4 & 78 & 72 & 72 & 56 & 74 & 70,4 & 24,8 \\
\hline \multirow[t]{2}{*}{ Av. não Experientes } & 84 & 60 & 28 & 28 & 30 & 46,0 & 92 & 66 & 44 & 50 & 62 & 62,8 & 36,5 \\
\hline & \multicolumn{13}{|c|}{ Profundidade de Olhos } \\
\hline Todos Avaliadores & 80 & 49 & 42 & 68 & 57 & 59,2 & 64 & 57 & 73 & 78 & 77 & 69,8 & 17,9 \\
\hline Av. Experientes & 82 & 62 & 56 & 74 & 56 & 66,0 & 68 & 62 & 78 & 80 & 72 & 72,0 & 9,1 \\
\hline \multirow{2}{*}{ Av. não Experientes } & 78 & 36 & 28 & 62 & 58 & 52,4 & 60 & 52 & 68 & 76 & 82 & 67,6 & 29,0 \\
\hline & \multicolumn{13}{|c|}{ Coloração de Pele } \\
\hline Todos Avaliadores & 78 & 76 & 48 & 33 & 57 & 58,4 & 79 & 65 & 59 & 52 & 70 & 65,0 & 11,3 \\
\hline Av. Experientes & 68 & 78 & 58 & 48 & 78 & 66,0 & 76 & 72 & 58 & 54 & 80 & 68 & 3,0 \\
\hline \multirow[t]{2}{*}{ Av. não Experientes } & 88 & 74 & 38 & 18 & 36 & 50,8 & 82 & 58 & 60 & 50 & 60 & 62 & 22,0 \\
\hline & \multicolumn{13}{|c|}{ Coloração de Polpa } \\
\hline Todos Avaliadores & 72 & 43 & 54 & 35 & 33 & 47,4 & 69 & 56 & 38 & 53 & 57 & 54,6 & 15,2 \\
\hline Av. Experientes & 76 & 42 & 60 & 40 & 44 & 52,4 & 58 & 60 & 36 & 56 & 60 & 54,0 & 3,1 \\
\hline \multirow[t]{2}{*}{ Av. não Experientes } & 68 & 44 & 48 & 30 & 22 & 42,4 & 80 & 52 & 50 & 50 & 54 & 57,2 & 34,9 \\
\hline & \multicolumn{13}{|c|}{ Coloração de Chips Após a Fritura } \\
\hline Todos Avaliadores & 84 & 73 & 69 & 89 & 97 & 82,4 & 88 & 75 & 80 & 97 & 100 & 88,0 & 6,8 \\
\hline Av. Experientes & 74 & 56 & 64 & 90 & 96 & 76,0 & 76 & 58 & 78 & 98 & 100 & 82,0 & 7,9 \\
\hline \multirow[t]{2}{*}{ Av. não Experientes } & 94 & 90 & 74 & 88 & 98 & 88,8 & 100 & 92 & 82 & 96 & 100 & 94,0 & 5,9 \\
\hline & \multicolumn{13}{|c|}{ Coloração de Palito Após a Fritura } \\
\hline Todos Avaliadores & 90 & 54 & 32 & 61 & 42 & 55,8 & 88 & 72 & 73 & 83 & 60 & 75,2 & 34,8 \\
\hline Av. Experientes & 88 & 62 & 36 & 58 & 32 & 55,2 & 94 & 78 & 82 & 80 & 50 & 76,8 & 39,1 \\
\hline Av. não Experientes & 92 & 46 & 28 & 64 & 52 & 56,4 & 82 & 66 & 64 & 86 & 70 & 73,6 & 30,9 \\
\hline
\end{tabular}

Nota: $* \Delta \%$ - Aumento nas médias de porcentagem de coincidência com o uso das escalas diagramáticas em relação às porcentagens sem o uso das escalas. * $\Delta \%$ - Increase in average percentage of coincidence with the use of diagrammatic scales towards percentages without the use of scales.

Fonte: Autoria própria. Own authorship. 
Outro critério utilizado para avaliar a eficácia das escalas diagramáticas foi a porcentagem de coincidência entre as notas atribuída pelos avaliadores (antes e após o uso das escalas) com as notas reais. Sem o uso das escalas observou-se que para todos os caracteres as maiores coincidências ocorreram com as notas mais extremas (notas 1 ou 5) (Tabela 2). Por outro lado, as menores porcentagens de coincidência foram atribuídas à nota 3 para formato de tubérculos, profundidade de olhos, coloração de palito e de chips após a fritura, para os demais caracteres as menores coincidências variaram entre as notas 2 e 4 (Tabela 2). Isto provavelmente se justifica pelo fato de notas intermediárias possuírem intervalos definidos, e notas extremas possuírem limites mais amplos, uma vez que os valores não são limitados por um intervalo.

Quando se compara as porcentagens médias de coincidência entre os avaliadores experientes e não experientes, foram observados maiores valores para os avaliadores experientes para a maioria dos caracteres estudados, exceto coloração de palito e de chips após a fritura (Tabela 2).

Com o uso das escalas, fica evidenciado, aumento para todos os avaliadores nas porcentagens médias de coincidência para todos os caracteres. Este aumento foi da ordem de 30,1 e 34,8\% para textura da periderme e coloração de palito após a fritura respectivamente (Tabela 2). Quando se utilizam as escalas diagramáticas, também foram observados que as maiores porcentagens de coincidência ocorreram com as notas extremas, exceto para profundidade de olhos (Tabela 2).

$\mathrm{O}$ aumento das porcentagens de coincidência entre as notas atribuídas pelos avaliadores e as notas reais após o uso das escalas, evidencia a maior precisão dos avaliadores em atribuir as notas. Este aumento em precisão ocorreu tanto para os avaliadores experientes como para os não experientes, para todas as características (Tabela 2). Destaque para coloração de polpa e textura da periderme, em que, os avaliadores não experientes obtiveram aumento da ordem de 34,9 e 36,5\%, respectivamente (Tabela 2). Já os avaliadores experientes aumentaram a porcentagem média de coincidência em 39,1\% para coloração de palito após a fritura (Tabela 2). Quando se compara os dois grupos de avaliadores, observa-se a maior porcentagem de coincidência para os avaliadores experientes em relação aos avaliadores não experientes para todos os caracteres, exceto para coloração de polpa e de chips após a fritura (Tabela 2).

Com o uso das escalas, as diferenças entre avaliadores experientes e não experientes se tornam mínimas, o que demonstra que o uso das escalas proporcionou resultados semelhantes independente da experiência. Provavelmente isto se justifica pelo fato de avaliadores experientes já possuírem em mente um padrão de avaliação mais próximo do real. Por outro lado, os avaliadores sem experiência ficam mais atentos aos detalhes das escalas, por não possuírem qualquer imagem fixada da realidade, o que explica os maiores aumentos médios proporcionado após o uso das escalas para estes avaliadores.

As escalas apresentam-se como uma ferramenta eficaz para a padronização das avaliações dos caracteres que compõe a aparência geral dos tubérculos, coloração de chips e palito após a fritura, haja vista a falta de um sistema padrão de avaliação. 


\section{CONCLUSÃO}

O uso das escalas diagramáticas mostrou-se eficaz, aumentando a reprodutibilidade das notas atribuídas pelos avaliadores.

\section{AGRADECIMENTOS}

A Fundação de Apoio à Pesquisa do Estado de Minas Gerais (FAPEMIG), por concessão de bolsa ao primeiro autor; ao Conselho Nacional de Desenvolvimento Científico e Tecnológico $(\mathrm{CNPq})$, por auxílio financeiro; e ao Programa de Melhoramento Genético de Batata da Universidade Federal de Lavras (Probatata), por apoio logístico.

\section{REFERÊNCIAS BIBLIOGRÁFICAS}

CAMPBELL, C. L.; MADDEN, L. V. Introduction to Plant Disease Epidemiology. New York: J WILEY, 1990. 532 p.

CARMO, E. L.; PADUA, J. G.; DIAS, J. P. T.; DUARTE, H. S. S.; DUARTE FILHO, J.; LEONEL M. Desempenho de cultivares nacionais e estrangeiras de batata em duas condições ambientais do Sul de Minas Gerais. Horticultura Brasileira, Recife, v. 27, n. 2, p.3352-3358, 2009. http://www.abhorticultura.com.br/EventosX/Trabalhos/EV_3/A2179_T3312_Comp.pdf. Acesso em: 04 set. 2019.

DUARTE, H. S. S.; ZAMBOLIM, L.; CAPUCHO, A. S.; JÚNIOR, A. F. N.; ROSADO, A. W. C.; CARDOSO, C. R.; MIZUBUTI, E. S. G. Development and validation of a set of standard area diagrams to estimate severity of potato early blight. European Journal of Plant Pathology, Heidelberg, v. 137, n. 2, p. 249-257, 2013. Disponível em: https://link.springer.com/content/pdf/10.1007/s10658-013-0234-3.pdf. Acesso em: 05 set. 2019.

DOLINSKI, M. A.; DUARTE, H. D. S. S.; SILVA, J. B.; MIO, L. L. M. Development and validation of a standard area diagram set for assessment of peach rust. European Journal of Plant Pathology, Heidelberg, v. 4, n. 4, p.817-824, 2017. Disponível em: https://link.springer.com/content/pdf/10.1007/s10658-016-1138-9.pdf. Acesso em: 05 set. 2019.

FIGUEIREDO, P. G.; TANAMATI, F. Y.; MARTINS, D; BICUDO, S. J.; CURCELLI, F. Cultivares, qualidade de tubérculos e comercialização da batata no Brasil. Revista Raízes e Amidos Tropicais, Botucatu, v. 7, n. 1, p.42-52, 2011. Disponível em: http://energia.fca.unesp.br/index.php/rat/article/view/1078. Acesso em: 02 set. 2019.

GARCIA, E. L.; CARMO, E. L. D.; PÁDUA, J. G. D.; LEONEL, M. Potencialidade de processamento industrial de cultivares de batatas. Ciência Rural, Santa Maria, v. 45, n. 10, p.1742-1747, 2015. Disponível em: https://www.scielo.br/scielo.php?pid=S010384782015001001742\&script=sci_arttext. Acesso em: 30 mai. 2020. 
HAYASHI, P. Variedade cupido: nova opção para mercado fresco. Batata Show, Itapetininga, v. 1, n. 3, p.14, 2001.

INSTITUTO BRASILEIRO DE GEOGRAFIA E ESTATÍSTICA - IBGE. Levantamento Sistemático da Produção Agrícola. Indicadores IBGE, Brasília, v. 30, n. 1, p.43-48, 2019. Disponível

em: https://biblioteca.ibge.gov.br/visualizacao/periodicos/2415/epag_2019_dez.pdf. Acesso em: 30 mai. 2020.

JEMISON, J. M.; SEXTON, P.; CAMIRE, M. E. Factors influencing consumer preference of fresh potato varieties in Maine. American Journal of Potato Research, Ann Arbor, v. 85, n. 2, p.140-149, 2008. Disponível em: https://link.springer.com/content/pdf/10.1007/s12230-0089017-3.pdf. Acesso em: 20 set. 2019.

JULIATTI, F. C.; CRATO, F. F. D.; JULIATTI, F. C.; COUTO, K. R.; JULIATTI, B. C. M. Escala diagramática para avaliação da severidade de mofo branco em soja. Bioscience Journal, Uberlândia, $\quad$ v. 29, p.676-680, 2010. Disponível em: https:http://www.seer.ufu.br/index.php/biosciencejournal/article/view/22440. Acesso em: 27 set. 2019.

LI, X. Q.; JONG, H.; JONG, D. M.; JONG W. S. Inheritance and genetic mapping of tuber eye depth in cultivated diploid potatoes. Theoretical and Applied Genetics, Heidelberg, v. 110, n. 6, p.1068-1073, 2005. Disponível em: https://link.springer.com/content/pdf/10.1007/s00122005-1927-6.pdf. Acesso em: 25 set. 2019.

MINISTÉRIO DA AGRICULTURA, PECUÁRIA E ABASTECIMENTO - MAPA. Instruções para execução dos ensaios de distinguibilidade, homogeneidade e estabilidade de cultivares de batata (Solanum tuberosum L.). Disponível em: https://www.gov.br/agricultura/pt-br/assuntos/insumos-agropecuarios/insumosagricolas/protecao-de-cultivar/agricolas. Acesso em: 30 mai. 2020.

MUNSELL, A. H. Munsell color charts for plants tissues. 2. ed. Baltimore: Macbeth div. of Kollmorgan Corp, 1977. 40 p.

NUTTER JUNIOR, F. W.; TENG, P. S.; SHOKES, F. M. Disease assessment terms and concepts. Plant Disease, St. Paul, v. 75, n. 1, p.1187-1188, 1991.

PINTO, C. A. B. P.; TEIXEIRA, A. L.; NEDER, D. G.; ARAÚJO, R. R.; SOARES, A. R.; RIBEIRO, G. H.; LEPRE, A. L. Potencial de clones elite de batata como novas cultivares para Minas Gerais. Horticultura Brasileira, Recife, v. 28, n. 4, p.399-405, 2010. Disponível em: https://www.scielo.br/scielo.php?pid=S0102-05362010000400004\&script=sci_arttext. Acesso em: 30 mai. 2020.

RIBEIRO, G. H. M. R.; PINTO, C. A. B. P.; FIGUEIREDO, I. C. R.; MOREIRA, C. M.; LYRA, D. H. Selection of families for tubers appearance and tolerance to elevated temperatures in potato. Bragantia, Campinas, v. 73, n. 4, p.390-398, 2014. Disponível em: https://www.cabdirect.org/cabdirect/abstract/20153159925. Acesso em: 25 set. 2019. 
TEAM, R. C. R: A language and environment for statistical computing. Vienna: R Foundation for Statistical Computing, 2017. Disponível em: https://www.R-project.org/. Acesso em: 25 set. 2019. 